\title{
Prevalence of extended spectrum B lactamase producing E.coli and Klebsiella SPP isolated in a tertiary care hospital, Gujarat
}

\author{
Assudani H. ${ }^{\text {, Gusani J. }}{ }^{2}$ \\ ${ }^{1}$ Dr. Hitesh Assudani, Associate Professor, Department of Microbiology, Gujarat Adani Institute of Medical Science, \\ Bhuj, Kutch, Gujarat, India, ${ }^{2}$ Dr. Jigar Gusani, Associate Professor, Department of Microbiology, Dr. N D Desai Faculty \\ of Medical Science \& Research, Nadiad Gujarat, India.
}

Corresponding Author: Dr. Jigar Gusani, Associate Professor, Department of Microbiology, Dr. N D Desai Faculty of Medical Science \& Research, Nadiad Gujarat, India. E-mail: researchguide86@gmail.com

\begin{abstract}
Background: Antibiotic resistance among gram negative bacilli is a rapidly expanding problem due to the organism's ability to mutate and to acquire the transmit plasmid and other genetic elements encoding resistance genes. Objective: This study was conducted to know the prevalence of ESBLs in E. coli and Klebsiella spp. isolates obtained from clinical samples. Material and Methods: A detailed history was taken and Performa was filled for each patient documenting age, sex, history of illness was obtained. Study was conducted at microbiology Department, Gujarat Adani Institute of Medial Sciences, Bhuj from May 2014 to Dec 2015. Total 2500 clinical samples like Urine, Sputum, Blood, Pus, CSF, Pleural fluid were collected in sterile containers. Samples from which E.coli and Klebsiella spp were isolated were considered for this study. Detection of ESBL was done as per CLSI guidelines. Results: Total 2500 clinical samples were tested for culture and sensitivity during August 2015 to July 2017. Out of this 500 samples showed growth of E. coli and Klebsiella spp. Among 500 isolates coli had 268 and from them 189 were ESBL positive. Similarly 232 were isolates from Klebsiella spp and among them 185 were positives for ESBL. Conclusion: In the present study, ESBL prevalence was $49.99 \%(E$. coli $=50.53 \%$ and $K$. pneumoniae $=49.46 \%)$. A moderately high prevalence of ESBL producing E. coli and K. pneumoniae was observed and confirmed in the urine, sputum, pus, CSF and Blood. A strict hospital infection control policy and a prudent anti-microbials use regimens are to be adopted by the physicians.
\end{abstract}

Key words: Bhuj, E.coli, extended spectrum B lactamase, Gram negative bacilli

\section{Introduction}

Antibiotic resistance is one the biggest threat that the world is facing currently. Antibiotic resistance among gram negative bacilli is a rapidly expanding problem due to the organism's ability to mutate and to acquire the transmit plasmid and other genetic elements encoding resistance genes [1]. The first report of plasmid encoded B lactamases capable of hydrolysing the Extended spectrum cephalosporins was published in 1983 [2].

B lactam antibiotics are one of the most commonly used antimicrobials against bacterial infection. In recent years emergence of resistance of these antimicrobials agents due to production of B lactamases has become serious global health concern. It leads to antibiotic ineffective, increase severity of illness and cost of treatment [3]. These enzymes are numerous and they

Manuscript received: $5^{\text {th }}$ June 2019

Reviewed: $14^{\text {th }}$ June 2019

Author Corrected: $20^{\text {th }}$ June 2019

Accepted for Publication: $25^{\text {th }}$ June 2019 mutate continuously in response to overuse or misuse of B lactam antibiotics and have lead to the development of extended spectrum B lactamases (ESBL). Risk factors for infection with ESBL producing organism are prolong antibiotic usage, ICU stay, Recent invasive procedures, Pressure sores, anaemia, permanent urinary catheter [4]. This study was conducted to know the prevalence of ESBLs in E. coli and Klebsiella spp. isolates obtained from clinical samples.

\section{Material and Method}

Study setting, duration and type of study- Study was conducted at microbiology Department, Gujarat Adani Institute of Medial Sciences, Bhuj from May 2014 to Dec 2015.

Sampling method and sample size calculation- Total 2500 clinical samples like Urine, Sputum, Blood, Pus, CSF, Pleural fluid were collected in sterile containers. 


\section{Original Research Article}

Samples from which E. coli and Klebsiella spp were isolated were considered for this study.

Ethical approval and informed consent- Institutional ethical committee permission was obtained. Consent was taken from all the patients.

Inclusion criteria- Patients who were willing to participate and give consent.

Exclusion criteria- Patients who had systemic disease and those who were not willing to participate.

A detailed history was taken and Performa was filled for each patient documenting age, sex, history of illness was obtained. Detection of ESBL was done as per CLSI guidelines. Screening and phenotypic confirmation tests were performed for all E. coli, Klebsiella spp. as per CLSI guidelines which is described below [5].

Screening test: Mueller Hinton agar plates were inoculated with standardized inoculum ( 0.5 McFarland standard) of the isolate to form a lawn culture. Disks of

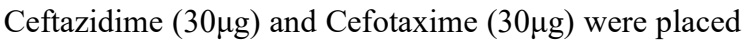
on inoculated Mueller Hinton agar plates. Plates were inverted and incubated at $35 \pm 2^{\circ} \mathrm{C}$ in ambient air for 16 to 18 hours. Zone of inhibition was measured. Ceftazidime $\leq 22 \mathrm{~mm}$ and/or Cefotaxime $\leq 27 \mathrm{~mm}$ were taken as indicator of suspicion for ESBL production. Such isolates are subjected to testing for phenotypic confirmation.

Phenotypic confirmation by combination disk test: Mueller Hinton agar plates were inoculated with standardized inoculum ( $0.5 \mathrm{Mc}$ Farland standard) of the isolate to form a lawn culture. Disks of Cefotaxime (30 $\mu \mathrm{g})$, Ceftazidime $(30 \mu \mathrm{g})$, Cefotaxime plus clavulanic acid $(30 \mu \mathrm{g} / 10 \mu \mathrm{g})$, Ceftazidime plus clavulanic acid (30 $\mu \mathrm{g} / 10 \mu \mathrm{g})$ are placed on inoculated Mueller Hinton agar plate. Plates were incubated at $35 \pm 20 \mathrm{C}$ in ambient air for 16 to 18 hours. Zone of inhibition was measured.

An increase of $\geq 5 \mathrm{~mm}$ in zone diameter with any of the antibiotic tested in combination with clavulanic acid versus tested alone was taken as indication of ESBL production by the isolates. Increase in zone of inhibition of $\leq 5 \mathrm{~mm}$ was considered as negative for ESBL production.

ESBL isolates which were resistant to Cefoxitin were not considered for the study. This is to exclude associated Amp C type of B lactamases [6,7].

\section{Results}

Total 2500 clinical samples were tested for culture and sensitivity during August 2015 to July 2017. Out of this 500 samples showed growth of E. coli and Klebsiella spp.

Table-1: Distribution as per gender.

\begin{tabular}{|c|c|c|c|}
\hline Sex & ESBL & Non ESBL & Total \\
\hline Female & 260 & 86 & 346 \\
\hline Male & 114 & 40 & 154 \\
\hline Total & $\mathbf{3 7 4}$ & $\mathbf{1 2 6}$ & $\mathbf{5 0 0}$ \\
\hline
\end{tabular}

Out of all ESBL positive isolates 374, (260) $69.51 \%$ were females and (114) $30.49 \%$ were Males.

Table-2: Distribution of isolates.

\begin{tabular}{|c|c|c|c|c|c|c|}
\hline Sample & Total & $\begin{array}{c}\text { E. coli } \\
\text { Urine }\end{array}$ & $\begin{array}{c}\text { ESBL positive } \text { E. } \\
\text { Coli }\end{array}$ & Klebsiella spp & $\begin{array}{c}\text { ESBL positive } \\
\text { Klebsiella spp. }\end{array}$ & Total \\
\hline Sputum & 539 & 81 & 60 & 69 & 52 & 150 \\
\hline Pus & 246 & 35 & 20 & 61 & 53 & 160 \\
\hline CSF & 42 & 3 & 1 & 45 & 43 & 80 \\
\hline Blood & 338 & 66 & 50 & 34 & 6 & 10 \\
\hline
\end{tabular}

Table 2 Describes Distribution of isolates. Strains isolated from different clinical specimens 399 from urine, 539 from sputum, 246 from pus, 42 from CSF and 338 from Blood. ESBL positive E. coli was highest from Urine followed by Sputum and Blood. Similarly, ESBL positive Klebsiella spp were from sputum followed by urine, pus and blood. 
Table-3: Prevalence of ESBL.

Original Research Article

\begin{tabular}{|c|c|c|}
\hline Organism & Total & ESBL \\
\hline E. coli & 268 & $189(50.53 \%)$ \\
\hline Klebsiella spp & 232 & $185(49.46 \%)$ \\
\hline Total & 500 & 374 \\
\hline
\end{tabular}

Table 3 Describes Prevalence of ESBL. Among 500 isolates E. coli had 268 and from them 189 were ESBL positive. Similarly 232 were isolates from Klebsiella spp and among them 185 were positives for ESBL.

\section{Discussion}

Many researchers have examined the prevalence of ESBL producing K. pneumonia, for example, in India; high prevalence of ESBL-producing $K$. pneumoniae strains has been reported by various groups. In the present study the prevalence of ESBL was $69.77 \%$ in $E$. coli and $79.74 \%$ in Klebsiella spp. Similar results are reported by Mathur et al [8] Some other authors like Sahni et al [9] has reported 32\% of ESBL. Percentage of ESBL-producing organisms ranged from $4 \%$ to $83 \%$ in India [10, 11]. Rodrigues et al [12] reported a lower prevalence for ESBL producers in Maharashtra.

They reported that four isolates $(8.5 \%)$ were positive ESBL-producers among $47 \mathrm{~K}$. pneumoniae isolates. This ratio probably reflects the emerging phase of ESBL production, which by now should have increased at the same location. This is understandable since the prevalence of ESBL producers in any hospital depends upon various factors such antibiotic policy, the carriage rate among the hospital personal, and the type of disinfectant used especially in the ICU [13].

In the present study female were more prone for ESBL isolates. Similar results are shown by Gupta $\mathrm{S}$ et al [4]. Mendelson G et al [14] and Bazzaz B et al [15] have reported more male proneness to ESBL.

Strains isolated from different clinical specimens 399 from urine, 539 from sputum, 246 from pus, 42 from CSF and 338 from Blood. ESBL positive E. coli was highest from Urine followed by Sputum and Blood. Similarly, ESBL positive Klebsiella spp were from sputum followed by urine, pus and blood. Recently, similar reports have been presented by Gupta et al [4].

In the recent years, a significant increase in ESBLproducing Klebsiella spp was also reported from the USA (42-44\%), Canada (4.9\%) [16], Spain (20.8\%) [17], Taiwan (28.4\%) [18], Turkey (78.6\%) [19], Algeria (20\%) [20] and China (51\%) [21].

Focusing on the epidemiology in Europe, there are considerable geographical differences in the occurrence of ESBLs. A recent survey of $1610 \mathrm{E}$. coli and $785 \mathrm{~K}$. pneumoniae isolates from 31 centres in 10 European countries found that, the prevalence of ESBL of these organisms ranged from as low as $1.5 \%$ in Germany to as high as $39-47 \%$ in Russia, Poland and Turkey [22].

This study demonstrated that the PCDDT was more sensitive for detecting ESBL than DDST, since it, detected $46.15 \%$ of ESBL, whereas PCDDT detected $50.76 \%$ of ESBL producers.

Presence of ESBLs can be masked by the expression of Amp C $\beta$-lactamase, which can be generated by chromosomal plasmid genes. Of the 384 clinical isolates of $K$. pneumoniae, 101 randomly selected isolates were screened for ESBL production by DDST and PCDDT. Of these 79 out of 101 isolates were found to be ESBL positive and 22 were ESBL negative, whereas, Duttaroy et al. from Gujarat India in 2005 reported $58 \%$ prevalence for ESBL producing $K$. pneumoniae, isolated from different clinical specimens using DDST [23].

Babypadmini et al. reported $40 \%$ prevalence for ESBL producing K.pneumoniae, in urinary isolates in Coimbatore, India in 2004 [24].

ESBL prevalence was $49.99 \%$ ( $E$. coli $=50.53 \%$ and $K$. pneumoniae $=49.46 \%$ ). It was high as compared to a study done in India [25], which reported nearly $40 \%$ of urinary isolates of E.coli and K. pneumoniae were ESBL positive. The highest isolation rate of ESBLs producing $K$. pneumoniae had been reported from the Latin America (54.4\%), the western Pacific (24.6\%) and Europe (22.6\%). The frequency of ESBL producing E.coli in these areas was reported to be $8.5 \%, 7.8 \%$ and $5.3 \%$, respectively.

Multi-centre studies involving major health-care facilities in other parts of the country are required to have a clearer picture of ESBL producing uropathogens. Further, molecular epidemiological studies of resistance genes among the uropathogens would provide us much needed details on bacterial clones circulating in this region. 


\section{Conclusion}

In the present study ESBL prevalence was $49.99 \%$ ( $E$. coli $=50.53 \%$ and $K$. pneumoniae $=49.46 \%)$. A moderately high prevalence of ESBL producing E.coli and $K$. pneumoniae was observed and confirmed in the urine, sputum, pus, CSF and Blood. A strict hospital infection control policies and a prudent anti-microbials use regimens are to be adopted by the physicians. It is essential and mandatory to have a regular and routine monitoring of ESBL producing clinical isolates in clinical laboratories.

\section{What this study adds to existing knowledge?}

Multi-center studies involving major health-care facilities in other parts of the country are required to have a clearer picture of ESBL producing uropathogens.

It is essential and mandatory to have a regular and routine monitoring of ESBL producing clinical isolates in clinical laboratories.

\section{Contribution from authors}

- Dr. Hitesh Assudani formulated the aims \& objectives with study design and helped in data collection from medical record department.

- Dr. Jigar Gusani contributed to the preparation of the manuscript and Data analysis.

Findings: Nil; Conflict of Interest: None initiated Permission from IRB: Yes

\section{References}

1. Nurul MA, Loo HKC, Subramaniam G, Wong EH, Selvi $\mathrm{P}$, Ho $\mathrm{S}$ et al. Faecal prevalence of extendedspectrum B- lactamase (ESBL)-producing coliforms in a geriatric population and among haematology patients. Malaysian J Pathol 2005;27(2):75-81.

2. Ali AM, Rafi S, Qureshi AH. Frequency of Extended Spectrum Beta Lactamase Producing Gram Negative Bacilli among Clinical Isolates at Clinical Laboratories of Army Medical College, Rawalpindi. http://ayubmed. edu.pk/ JAMC/PAST/16-1/Aarif.htm

3. Yazdi M, Nazemi A, Mirinargasi M, Jafarpour M, Sharifi SH. Genotypic versus Phenotypic methods to detect extended-spectrum beta-lactamases (ESBLs) in uropathogenic Escherichia coli.Ann Biol Res 2012; 3: 2454-8.

4. Gupta S, Maheshwari V. Prevalence of ESBLs among Enterobacteriaceae and their antibiotic resistance pattern from various clinical samples. Int $\mathrm{J}$ Curr Microbiol App Sci 2017;6(9):2620-8. DOI: https://doi. org/ 10.20546/ijcmas. 2017.609.323

5. Clinical laboratory standards institute. Performance standard for antimicrobial susceptibility testing; seventeenth informational supplement M100-S17, vol 27 No.1. Clinical laboratory standards institute. Wayne PA. USA 2007.

6. Mohamudha Parveen R, Harish BN, Parija SC. Ampc Beta lactamases among gram negative clinical isolates from a tertiary hospital, South India. Braz J Microbiol. 2010;41(3):596-602. DOI:10.1590/S1517-8382201 00 00300009. Epub 2010 Sep 1.

7. Shashwati N, Kiran T, Dhanvijay AG. Study of extended spectrum $\beta$-lactamase producing Enterobacteriaceae and antibiotic coresistance in a tertiary care teaching hospital. J Nat Sci Biol Med. 2014;5(1):30-35. DOI:10.4103/0976-9668.127280.

8. Mathur P, Kapil A, Das B, Dhawan B. Prevalence of extended spectrum beta lactamase producing gram negative bacteria in a tertiary care hospital. Indian $\mathrm{J}$ Med Res. 2002;115:153-7.

9. Grover N, Sahni AK, Bhattacharya S. Therapeutic challenges of ESBLS and AmpC beta-lactamase producers in a tertiary care center. Med J Armed Forces India. 2013;69(1):4-10. DOI: 10.1016/j.mjafi. 2012.02. 001. Epub 2012 Jul 17.

10. Hansotia JB, Agarwal V, Pathak AA, Saoji AM. Extended spectrum beta-lactamase mediated resistance to third generation cephalosporins in Klebsiella pneumoniae in Nagpur, central India. Indian J Med Res. 1997;105:158-61.

11. Lal P, Kapil A, Das BK, Sood S. Occurrence of TEM \& SHV gene in extended spectrum betalactamases (ESBLs) producing Klebsiella sp. isolated from a tertiary care hospital. Indian J Med Res. 2007; 125(2):173-8.

12. Rodrigues C, Joshi P, Jani SH, Alphonse M, Radhakrishnan R, Mehta A. Detection of $\beta$-lactamases in nosocomial gram negative clinical isolates. Indian $\mathrm{J}$ Med Microbiol. 2004;22(4):247-50.

13. Ananthan S, Subha A. Cefoxitin resistance mediated by loss of a porin in clinical strains of Klebsiella pneumoniae and Escherichia coli. Indian J Med Microbiol. 2005;23(1):20-3. 
14. Mendelson G, Hait V, Ben-Israel J, Gronich D, Granot E, Raz R. Prevalence and risk factors of extended-spectrum beta-lactamase-producing Escherichia coli and Klebsiella pneumoniae in an Israeli longterm care facility. Eur J Clin Microbiol Infect Dis. 2005;24(1):17-22. DOI:10.1007/s10096-004-1264-8

15. Bazzaz BS, Naderinasab M, Mohamadpoor AH, Farshadzadeh Z, Ahmadi S, Yousefi F. The prevalence of extended-spectrum beta-lactamase-producing Escherichia coli and Klebsiella pneumoniae among clinical isolates from a general hospital in Iran. Acta Microbiol Immunol Hung. 2009;56(1):89-99. DOI: 10.1556/ AMicr. 56.2009.1.7.

16. Saurina G, Quale JM, Manikal VM, Oydna E, Landman D. Antimicrobial resistance in Enterobacteriaceae in Brooklyn, NY: epidemiology and relation to antibiotic usage patterns. J Antimicrob Chemother. 2000; 45 (6): 895-8. DOI:10.1093/jac/45.6.895

17. Romero ED, Padilla TP, Hernández AH, Grande RP, Vázquez MF, García IG. Prevalence of clinical isolates of Escherichia coli and Klebsiella spp. producing multiple extended-spectrum beta-lactamases. Diagn Microbiol Infect Dis. 2007;59(4):433-7. Epub 2007 Oct 29. DOI:10.1016/j.diagmicrobio.2007.06.007

18. Kuo KC, Shen YH, Hwang KP. Clinical implications and risk factors of extended-spectrum betalactamase-producing Klebsiella pneumoniae infection in children: a case-control retrospective study in a medical center in southern Taiwan. J Microbiol Immunol Infect. 2007;40(3):248-54.

19. Hoşoğlu S, Gündes S, Kolayli F, Karadenizli A, Demirdağ K, Günaydin $\mathrm{M}$ et al. Extended-spectrum beta-lactamases in ceftazidime-resistant Escherichia coli and Klebsiella pneumoniae isolates in Turkish hospitals. Indian J Med Microbiol. 2007;25(4):346-50. DOI: $10.4103 / 0255-0857.37336$

20. Messai $Y$, Iabadene $H$, Benhassine $T$, Alouache S, Tazir M, Gautier V, et al. Prevalence and characterization of extended-spectrum beta-lactamases in Klebsiella pneumoniae in Algiers hospitals (Algeria). Pathol Biol (Paris). 2008;56(5):319-25. DOI: 10.1016/j. patbio. 2008.05.008. Epub 2008 Jun 27.

21. Xiong Z, Zhu D, Zhang Y, Wang F. [Extendedspectrum beta-lactamase in Klebsiella pneumoniae and Escherichia coli isolates]. Zhonghua Yi Xue Za Zhi. 2002; 82(21):1476-9.

22. Goossens H; MYSTIC Study Group (Europe). MYSTIC program: summary of European data from 1997 to 2000. Diagn Microbiol Infect Dis. 2001;41 (4): 183-9. DOI: https://doi.org/10.1016/ S0732-8893(01) 00320-0

23. Duttaroy B, Mehta S. Extended spectrum b lactamases (ESBL) in clinical isolates of Klebsiella pneumoniae and Escherichia coli. Indian $\mathrm{J}$ Pathol Microbiol. 2005;48(1):45-8.

24. Babypadmini S, Appalaraju B. Extended spectrum lactamases in urinary isolates of Escherichia coli and Klebsiella pneumoniae - prevalence and susceptibility pattern in a tertiary care hospital. Indian $\mathrm{J}$ Med Microbiol. 2004;22(3):172-4.

25. Babypadmini S, Appalaraju B. Extended spectrum lactamases in urinary isolates of Escherichia coli and Klebsiella pneumoniae - prevalence and susceptibility pattern in a tertiary care hospital. Indian $\mathrm{J}$ Med Microbiol. 2004;22(3):172-4.

\section{How to cite this article?}

Assudani H, Gusani J.Prevalence of extended spectrum B lactamase producing E.coli and Klebsiella SPP isolated in a tertiary care hospital, Gujarat. Trop J Path Micro 2019;5(6):403-407. doi:10.17511/jopm.2019.i06.11. 